\title{
COMUNIDADES INDÍGENAS, EMPRESAS DEL LITIO Y SUS RELACIONES EN EL SALAR DE ATACAMA
}

\author{
INDIGENOUS COMMUNITIES, LITHIUM COMPANIES AND THEIR RELATIONS \\ IN THE SALAR DE ATACAMA
}

\author{
Hans Gundermann ${ }^{1}$ y Barbara Göbel ${ }^{2}$
}

\begin{abstract}
La importancia global creciente del litio otorga visibilidad a las regiones donde se produce. En el llamado "triángulo del litio" destaca el Salar de Atacama, en explotación desde la década de 1980 para la obtención de potasio y litio de salmueras. Menos conocidos son los efectos ambientales y sociales, así como los procesos sociales relacionados localmente con la minería de salares. Este tema aborda el artículo, destacando las relaciones que en el periodo se han sucedido entre empresas y comunidades atacameñas. Esos vínculos coevolucionan en uno y otro sentido. Los cursos de acción hacia las localidades circundantes y el municipio de San Pedro de Atacama tienen lugar al mismo tiempo que se forman actores locales y étnicos que van estableciendo demandas territoriales y socio culturales. Tales demandas van dirigidas en parte a las empresas mineras, discutiendo derechos territoriales, daños en los acuíferos y los ecosistemas del salar, usos alternativos del salar, redistribución de ganancias y participación. En el cambiante cuadro de vinculaciones comunidades-empresas estas desarrollan, ajustan e innovan términos de relación con las comunidades (del paternalismo a los valores compartidos) y aquellas también crean términos de relación dinámicos y estrategias (de la aceptación pasiva a formas de contraposición abierta). Lo hacen en escenarios (políticos, económicos, locales, nacionales y globales) que presentan oportunidades y abren posibilidades de acción o las restringen e impiden otras.
\end{abstract}

Palabras claves: minería de salares, comunidad atacameña, demandas locales y étnicas, escenarios de negociación.

The increasing global importance of lithium gives worldwide visibility to those regions where it is produced. In the so called lithium triangle, the salt flat of Atacama stands out as a major source of potassium and lithium, which have been extracted from mining brines since 1980. Less known are the environmental and social effects, as well as the social processes locally related to salt mining. This topic is addressed in this article by analyzing the relationships that in the period have occurred between companies and Atacameño communities. These links co-evolve in one direction or another. The actions aimed towards the surrounding communities and the local authorities of San Pedro de Atacama take place at the same time that local and ethnic actors are formed and make territorial and socio-cultural demands. Such demands are addressed to mining companies and involve land rights, damage to aquifers and saltwater ecosystems, alternative uses of the salt flats, redistribution of profits and participation. In the changing picture of community-company linkages, companies develop, adjust and innovate in terms of relationship with communities (from paternalism to shared values, for instance). Communities also create dynamic relationship terms and strategies (from passive acceptance to open forms of opposition). They do it in political, economic, local, national and global scenarios, which present opportunities and open possibilities for action, but which also restrict them and prevent others.

Key words: Salt mining, Atacameño community, local and ethnic demands, scenarios of negotiations.

El litio se ha convertido en los últimos años en una de las materias primas claves para la transición tecnológica hacia sistemas de movilidad y producción energética con bajas emisiones de dióxido de carbono․ Sepresentaentonces comoun nuevorecursoestratégico para la "economía verde". Esto corresponde al interés del Norte Global, también reflejado en los acuerdos internacionales sobre cambio climático, de establecer estilos de vida más sustentables y de desarrollar "tecnologías verdes" para el mercado global. Por sus características específicas -es el mineral más liviano y tiene una gran capacidad de almacenamiento eléctricoel litio es uno de los componentes esenciales para el desarrollo de generaciones de baterías más eficientes

\footnotetext{
${ }^{1}$ Instituto de Arqueología y Antropología (IAA), Universidad Católica del Norte. Calle Gustavo Le Paige 380, San Pedro de Atacama, Chile. hgunder@ucn.cl

${ }^{2}$ Instituto Iberoamericano de Berlín (IAI), Postdamer Strasse 37, Berlín, Alemania. goebel@iai.spk-berlin.de
} 
y flexibles, requeridas tanto por la movilidad eléctrica (por ejemplo, autos o camiones eléctricos o híbridoseléctricos) como por una matriz energética con mayor contribución de energía solar y eólica. Aunque el litio tiene una amplia gama de usos industriales tradicionales que incluyen lubricantes, vidrio, aire acondicionado, aluminio y farmacéuticos, es precisamente en el área de la tecnología de baterías que se ha dado, en los últimos años, el mayor incremento de la demanda internacional por este mineral.

La mayor competencia por el recurso litio y el creciente interés por asegurar la provisión de este mineral en el futuro han puesto en la mira de la economía global al llamado "triángulo del litio". Se trata de una región que abarca por el norte al Salar de Uyuni (Bolivia), por el oeste al Salar de Atacama (Chile) y en el este a una serie de salares del noroeste argentino (provincias de Jujuy, Salta y Catamarca). En el "triángulo del litio" se encuentra más del $70 \%$ de las reservas mundiales explotables de litio en salmueras. En comparación con otros lugares del mundo con reservas de litio importantes (por ejemplo, yacimientos en rocas de Australia o China, o en el mar como en Corea), el acceso al recurso mineral y su explotación es en los salares más fácil, tecnológicamente más simple y, por ende, económicamente más viable. Los salares del "triángulo del litio", además, se destacan por la cantidad, concentración y calidad de los depósitos, condiciones climáticas favorables con una alta tasa de evaporación y ausencia o baja cantidad de precipitaciones.

De esta manera, a pesar de la alta visibilidad social y mediática del litio se sabe hasta ahora relativamente poco sobre el desarrollo de esta minería desde una perspectiva local. Presentamos aquí algunos resultados de investigación, concentrándonos en el Salar de Atacama en la región chilena de Antofagasta. Nos interesa entender mejor las interacciones entre empresas mineras del litio, los pueblos originarios y también el Estado. Es el resultado de una actividad etnográfica progresiva, realizada a intervalos durante varios años y lograda a través de sucesivos contactos con personas, consulta de registros oficiales y elaboración de resultados parciales para su presentación en reuniones académicas. Intentamos otorgar visibilidad a los actores locales y supralocales involucrados, así como los marcos institucionales y normativos que dinamizan y a la vez delimitan su acción. Por tratarse de organizaciones, demandas y cursos de acción que se formulan y llevan a efecto fundamentalmente dentro de marcos institucionales y legales, representando el escenario o espacio social y político de las relaciones estudiadas, intentamos hacer visible la compleja de red de relaciones que en el Salar de Atacama se dan entre actores atacameños, empresas mineras y también agencias públicas.

\section{La Minería de Salares y el Litio}

La minería en el "triángulo del litio" se encuentra en distintas fases de desarrollo. En el Salar de Atacama (Región de Antofagasta, Chile) se explota desde 1984 litio para su posterior exportación hacia Estados Unidos, la Unión Europea y Asia (Japón, Corea, China, etc.). Así, por ejemplo, la Unión Europea cubrió en 2010 el 64\% de sus importaciones de litio desde allí (European Commission Raw Material Strategy Report 2010-2011). En 1998 se sumó el Salar del Hombre Muerto (provincias de Salta y Catamarca, Argentina) a la exportación de litio refinado (Proyecto Fénix de Minera del Altiplano con el accionista FMC Lithium). Desde el año 2014 se explota litio tanto en el Salar de Uyuni (Departamento de Potosí, Bolivia; Dirección de Evaporíticos de Bolivia de la COMIBOL) como en los salares argentinos de Olaróz-Cauchari (provincia de Jujuy; empresa Sales de Jujuy y Minera ExarPosco) y de Rincón (provincia de Salta; empresa Ady Resources), sin que todavía se haya alcanzado una producción de litio refinado a gran escala. En otros salares del noroeste argentino los proyectos mineros se hallan todavía en la fase de exploración (p.ej., en la Provincia de Salta: Salar Centenario, Salar de Arizaro, Salar de Pozuelos, Salar de Pocitos). Además, hay en todo el "triángulo del litio" numerosos yacimientos en salares, algunos de los cuales cuentan con concesiones mineras vigentes. Por ejemplo, en la Provincia de Salta el Salar de Cangrejillos; en la de Jujuy las salinas de Jama; en Chile, los salares de Maricunga y Pedernales y Punta Negra; en Bolivia, el extenso Salar de Coipasa (Figura 1).

Debido a su vinculación con estilos de vida más sustentables y tecnologías de vanguardia presentes en la "economía verde" el litio ha ganado en los últimos años visibilidad social y atención mediática. Se relaciona explotación del litio con imaginarios de un progreso rápido que entrelazan, los salares de las tierras altoandinas en las periferias de los estados nacionales con los centros de innovación tecnológica del Norte Global. El litio es en ese sentido un medio de teleconexión global. Particularmente en Argentina y Bolivia existe, además, la expectativa de poder generar grandes riquezas a través de una industrialización propia del litio. Otro reflejo del interés global por el litio es que este mineral haya sido clasificado en Chile, Argentina y Bolivia como recurso estratégico.

Sin embargo, la conexión discursiva entre el litio, sustentabilidad e imaginarios de progreso invisibiliza a las "insustentabilidades" que la minería del litio produce a nivel local. Ella se instala en 


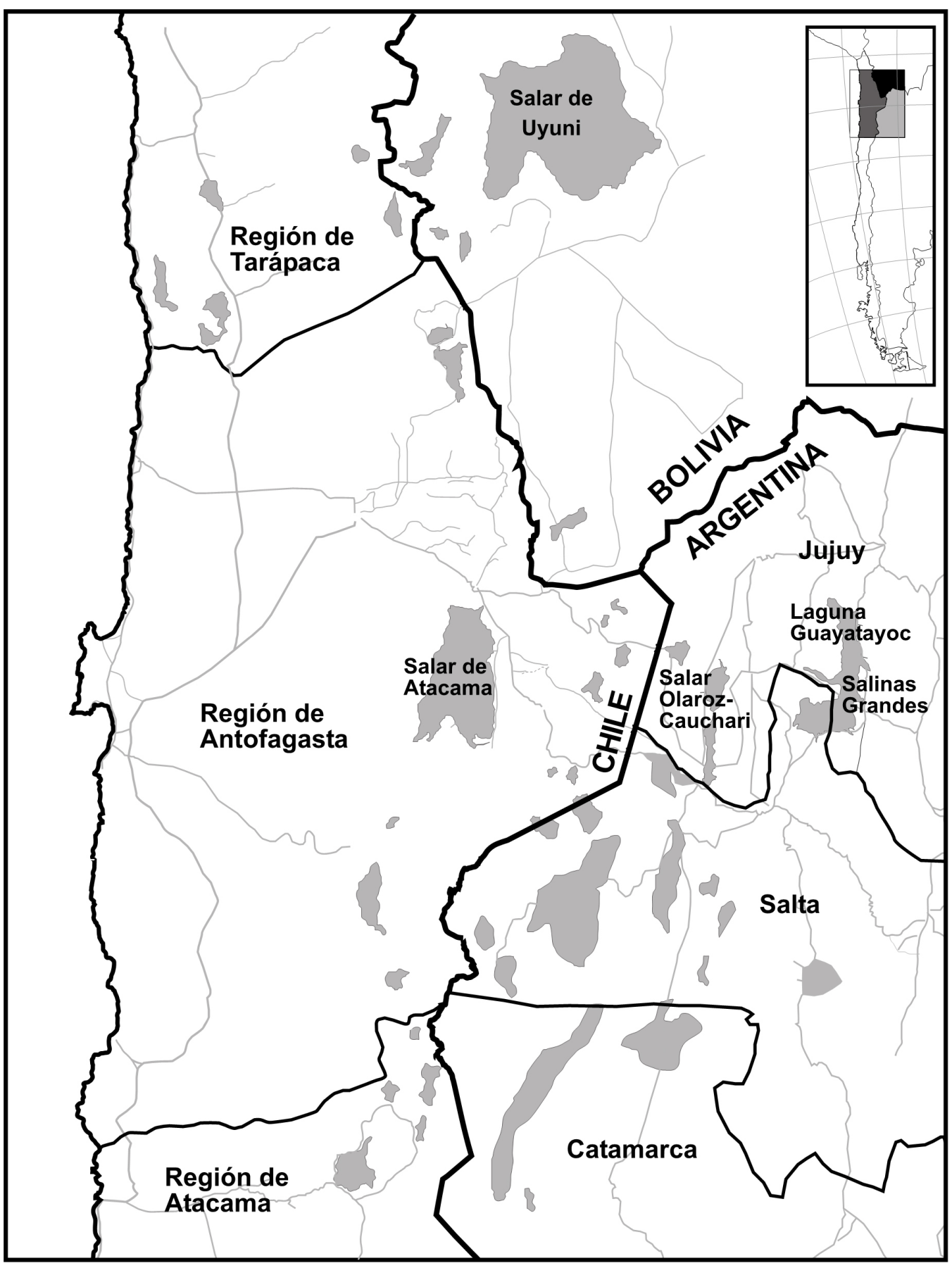

Figura 1. Región de salares con salmueras ricas en litio o "triángulo del litio" (elaboración propia). Specific region full of brines rich in lithium or "lithium triangle". 
salares que son ecosistemas muy frágiles que además se encuentran en desiertos o semidesiertos de altura con una vegetación escasa y dispersa. Gran parte de los pobladores que viven alrededor de los salares se autodefinen como indígenas o descendientes de pueblos originarios. En sus modos de vida, a pesar de las profundas transformaciones acaecidas, persiste un fuerte vínculo con los lugares y el entorno natural. Constituyen anclajes a la vez culturales y materiales de la identidad local y étnica, en tanto consideran los seres, las fuerzas, los elementos de la fisiografía y la topografía, así como las fronteras de los espacios que les conciernen. Ellos integran la memoria del ambiente y son el soporte físico de las biografías personales y familiares.

El "aterrizaje" de la minería del litio en el salar tiene una multiplicidad de efectos disruptivos en la naturaleza que ponen en evidencia el carácter invasivo de un proyecto extractivo en un ecosistema frágil. En ese contexto una de las preocupaciones centrales de la población local es el enorme consumo de agua de los emprendimientos mineros, tanto por la extracción de salmueras de los salares, como por los requerimientos de agua para el procesamiento de estas salmueras y el mantenimiento de los trabajadores. Otra preocupación gira alrededor de los efectos negativos que la minería del litio pueda tener para la flora y fauna del lugar (p.ej., flamencos, otras aves, vicuñas, insectos, microorganismos). En aquellos casos donde hay un aprovechamiento económico del salar por parte de la población local, ya sea a partir de la extracción de sal (p.ej., Salinas Grandes, provincias de Jujuy y Salta, Argentina), por la cría de ganado en los bordes del salar (p.ej., Salar de Olaróz-Cauchari, Provincia de Jujuy, Argentina) o a través del aprovechamiento del turismo de paisajes extremos (p.ej., Salar de Atacama en Chile) las empresas mineras son percibidas como invasores y competidores. Invasores de espacios territoriales respecto de los cuales cada vez con más definición e intensidad se plantean reclamos de pertenencia. Competidores por las tierras, las aguas, los minerales y otros recursos naturales del territorio que consideran y reivindican como propios. Por lo tanto, se presenta una evidente disociación entre, por un lado, los beneficios que obtienen las empresas mineras y la sociedad en general (a partir de la distribución que hace el Estado de los impuestos y rentas de la minería de litio) y, por el otro lado, los costos y riesgos ambientales, los impactos económicos y sociales en el presente y el futuro para la población local.

\section{Las Empresas Mineras en el Salar de Atacama}

La Sociedad Química y Minera (SQM) es una empresa especializada en la producción y distribución global de fertilizantes, yodo, potasio y químicos industriales (nitratos, cloruro de potasio, ácido bórico y cloruro de magnesio). Es uno de los principales productores en los rubros indicados (litio, boro, yodo, fertilizantes y otras sales) y opera a nivel internacional con oficinas de representación en 20 y clientes en 110 países. La Sociedad Química y Minera (SQM) fue en su origen (1968-1971) una empresa con capitales mixtos entre el Estado de Chile y la compañía Anglo Lautaro S.A. para reorganizar los remanentes de la industria del salitre en el Desierto de Atacama. Luego se estatiza durante el gobierno de Salvador Allende (1971) y mantiene esta condición hasta bien avanzado el periodo autoritario (1983), momento en el que se inicia su privatización (entre 1983 y 1986). Tiene la particularidad entre las empresas que explotan litio, mayoritariamente con capitales extranjeros, de tener hasta ahora una significativa participación de capitales y ejecutivos chilenos, incluido un pariente político de Augusto Pinochet en una posición de gran influencia en la propiedad y el directorio de la empresa.

Mantiene varias plantas de extracción y procesamiento instaladas en salares y depósitos de sales en roca, todos en el genéricamente llamado Desierto de Atacama. Las faenas y plantas principales se encuentran en el Salar de Atacama, la Pampa del Tamarugal, sector Lagunas, Salar de Llámara, yacimientos de María Elena y el parque industrial La Negra (en las afueras de la ciudad de Antofagasta). Como todas las empresas mineras de cierta envergadura, las oficinas principales se encuentran en Santiago y tributan allí. A todo lo anterior se suma una amplia estructura logística y una red internacional de comercialización de sus productos, entre los cuales se encuentra el litio. Un impulso decisivo en la internacionalización financiera de la empresa arranca en 1993 con la colocación de ADR en la bolsa de Nueva York. Y con ello se contó con los recursos (cerca de US\$300 millones) para instalaciones y plantas de extracción, evaporación y elaboración de cloruro de potasio, sulfato de potasio, carbonato de litio y ácido bórico. En 1995 se inicia la producción de cloruro de potasio y en 1997 la de carbonato de litio. Por la extensión de las pertenencias mineras y la riqueza de las salmueras SQM Salar se establece como el principal productor individual mundial de carbonato de litio desde salmueras, por sobre su competidora Rockwood Lithium que inició actividades en el mismo salar y con base en pertenencias mineras de la Corporación de Fomento de la Producción (CORFO) algunos años antes.

En 2012 se adjudicó una licitación para contratos de operación (explotación y elaboración) de litio, a la que había llamado el Ministerio de Minería en el gobierno de Sebastián Piñera. Los 
postulantes perdedores (el consorcio coreano Posco Consortium y la Sociedad Legal Minera NX UNO con capitales chilenos) reclamaron los resultados, se verificaron irregularidades y la licitación ganada se anuló, dejando pendiente para el gobierno siguiente mejores definiciones en esta materia. Desde 2015 es investigada por financiamiento irregular a políticos y campañas políticas de un amplio espectro de partidos y grupos. Esto se suma a sanciones por el rediseño de compañías en el conglomerado SQM, impulsado por el controlador chileno de la compañía, con consecuencias impositivas para el fisco nacional. Todo esto llevó a la compañía a una revisión interna que implicó la salida del gerente general histórico, cambios en la composición del directorio y la intervención de grupos accionarios extranjeros. Supuso también conflictos con la justicia chilena, el organismo de control financiero del Estado, el Servicio de Impuestos Internos (SII) y un desplome de su imagen de empresa exitosa. Y también a una disputa con CORFO (Corporación de Fomento de la Producción), dueña de las pertenencias mineras que explota SQM Salar. Como telón de fondo se encuentra presente el pasado pinochetista del principal controlador nacional ${ }^{2}$.

Rockwood Lithium, por su parte, tiene antecedentes, trayectoria y una inserción en las cadenas globales de valorización del litio distinta a la de SQM. Por lo demás, su tamaño (volumen de operaciones y personal) es también más pequeño. La empresa y sus instalaciones industriales arrancan antes que SQM, a partir del acuerdo generado en 1980 entre CORFO y una empresa estadunidense con experiencia en litio (Foote Mineral) que pasa a ser controladora del proyecto. En 1984, es decir, algo más de una década antes que SQM, inicia la extracción de salmuera en el salar y la producción de carbonato de litio (con una planta ubicada en el parque industrial La Negra, en los altos de Antofagasta). La empresa gusta presentarse como innovadora en los procesos de extracción y refinamiento básico de litio. En 1989 CORFO vende su participación a Foote Mineral Co. Más tarde, Foote se asocia con el holding Rockwood Lithium, quien luego pasa a controlar la empresa, contratos e instalaciones mineras en Chile. El consorcio internacional Rockhwood Lithium con oficinas, plantas y laboratorios en Estados Unidos, Alemania y Chile se especializa en compuestos de litio. En 2015 se anuncia oficialmente que Albemarle, una empresa química norteamericana, compró Rockwood Lithium y, con ello, se posiciona como uno de los principales actores mundiales en la producción de litio y en la elaboración para su empleo en productos finales. En Chile, la acción reciente de Rockwood - Albemarle destaca por dos hechos de interés. Primero, la gestación de un acuerdo con CORFO que mejora sustancialmente los términos de la concesión de explotación en el Salar de Atacama en favor del fisco chileno y, segundo, un notable cambio de dirección en la política de relaciones de la empresa con las comunidades indígenas aledañas, abriéndose ahora a entregar una inédita participación.

Mientras Rockwood - Albemarle busca alinear, exitosamente, su desenvolvimiento con la política del litio que el gobierno de Chile viene formulando desde 2014, la relación de SQM con CORFO entró en controversias y se judicializó, buscando en paralelo asegurar su producción de litio mediante la compra de activos mineros de litio en el extranjero. En ambos casos se aprecian medidas adoptadas los últimos dos años, tendientes a sostener y proyectar su participación en los mercados globales del litio. En un caso, asegurando la provisión de sales para alimentar la cadena de valoración del litio en la que es actor; en el otro, intentando sostener su participación en la provisión de compuestos básicos de litio en el mercado mundial.

\section{La Formación de la Comunidad Indígena: Organizaciones y Demandas Territoriales en Atacama}

La formación de las agrupaciones locales atacameñas bajo la figura legal de Comunidad Indígena se lleva a efecto en 1994 y 1995 mediante la Ley $\mathrm{N}^{\circ} 19.253$ de 1993 o Ley Indígena. Sociológicamente corresponden a poblados y localidades rurales de los municipios de Calama, Ollagüe y San Pedro de Atacama, que en su conjunto conforman la Provincia de El Loa. Una parte de sus integrantes vive en los poblados y sectores de origen, mientras que la mayoría reside fuera de allí en centros urbanos regionales, es asalariado en empresas mineras, actividades relacionadas, empleado en servicios o desarrolla pequeño comercio, y visita con más o menos frecuencia la comunidad de origen. Sin la base territorial de las primeras y con otros fines, en Calama, Ollagüe y el mismo San Pedro de Atacama se ha formado un gran número de Asociaciones Indígenas.

Una diversidad de formas de organización se encuentran presentes en las localidades atacameñas. Mantienen más o menos vigencia y actividad según intereses internos y relaciones con agencias públicas y actores económicos regionales. La Comunidad Indígena asume la titularidad de las tierras comunitarias y lo que se encuentra en ellas, las aguas de riego y bebida para las personas y animales, otros bienes colectivos (edificaciones y sedes comunitarias, por ejemplo) y la representación jurídica y sociopolítica del grupo y sus bienes. La Junta de Vecinos, normalmente solapada con la Comunidad Indígena y de creación mucho más antigua, se ocupa de la relación con el municipio y con 
algunos servicios públicos. A cada agrupación local atacameña corresponde una Comunidad Indígena. Es un órgano independiente y autónomo, formalmente, de otras organizaciones de la comunidad. Lo es también de las organizaciones de segundo nivel y de entidades de representación más amplios como el gobierno municipal. En los hechos se dan relaciones de complementariedad. Pero también de separación: acciones paralelas, roces y conflictos entre unas y otras organizaciones de la entidad local, y entre niveles organizativos.

Las Comunidades Indígenas, por impulso propio $\mathrm{y}$ en un marco de oportunidades institucionales y políticas muy favorables, se conformaron rápidamente en actores principales de la formulación de demandas colectivas y la reivindicación y defensa de tierras, aguas y otros recursos naturales ${ }^{3 .}$ La definición y activación de una base de demandas territoriales tiene lugar hacia finales de la década de 1990. Podemos aquí apuntar la concurrencia, progresiva y con efectos acumulativos, de varios componentes: la titulación de tierras y el saneamiento de aguas atacameñas que considera como una de sus medidas iniciales la Ley Indígena de 1993 y, en relación directa con ello, el acuerdo entre CONADI (Corporación Nacional de Desarrollo Indígena) y el Ministerio de Bienes Nacionales (MBN) y el de CONADI con la Dirección General de Aguas (DGA); la definición de las tierras y territorios indígenas atacameños y quechuas entre 1996 y 1999; la creación de Áreas de Desarrollo Indígena (ADI) en el Salar de Atacama (1997) y el Alto Loa (2003) y, por cierto, la propia acción de comunidades, asociaciones atacameñas y agrupaciones, o la representación de segundo nivel, como el Consejo de Pueblos Atacameños, el Consejo Directivo de las Áreas de Desarrollo Indígena y la consejería atacameña ante el Consejo Nacional de CONADI.

Suele señalarse que la principal amenaza que se cierne en el desierto sobre las comunidades atacameñas es la usurpación de sus aguas corrientes de uso ancestral. Una parte de aquellas (Calama, Chiu-chiu y Lasana) fueron inscritas a nombre de sus tenedores y usuarios históricos ya en el año 1984 con la aplicación del Código de Aguas de 1981. Por no representar esas inscripciones una suficiente protección a la enajenación por terceros y por haberse activado ventas de derechos particulares de agricultores no indígenas o no organizados como tales en Quillagua, oasis de Calama, Chiu-chiu y Lasana (todos en la cuenca del río Loa), se procedió entre 1995 y 1998 a la inscripción de aguas de la cuenca del Salar de Atacama y el Loa a nombre de comunidades indígenas y asociaciones indígenas de regantes ${ }^{4}$. El abogado que prestó servicios a la CONADI en esta materia señala que "fueron reconocidos judicialmente e inscritos en el registro conservatorio la gran mayoría de los derechos de agua de propiedad ancestral de las comunidades atacameñas ( 70 derechos a favor de 18 organizaciones indígenas, por un caudal total de 2.278,8 1/s)" (Cuadra 2000:111).

Las aguas subterráneas, en cambio, no quedaron sujetas a resguardos especiales, sino a los términos del Código de Aguas (Ley $\mathrm{N}^{\circ} 20.304$ ) que permite la transacción de derechos de aprovechamiento. En parte, porque el plan inicial de titular todas las tierras atacameñas históricas se ha cumplido solo parcialmente; en parte, porque la legislación de aguas ha seguido en lo sustancial sujeta a una lógica liberal de propiedad individual y circulación mercantil de derechos, incluyendo a las aguas subterráneas. Una evaluación gruesa de lo ocurrido estas últimas décadas indica que se han explorado por particulares aguas subterráneas en todo el espacio territorial reivindicado por las comunidades atacameñas y fuera de él, en la Provincia de El Loa y en el resto de la región de Antofagasta donde se presume la existencia de acuíferos subterráneos. Cuando ello se ha realizado en tierras comunitarias atacameñas, tituladas o demandadas, las exploraciones y la inscripción de derechos por particulares ha sido objeto de amparos judiciales y oposiciones de inscripción ante tribunales. Un caso emblemático es el desistimiento en 2007 por parte de la empresa Minera Escondida (BHP Billiton), debido a la presión de las organizaciones indígenas afectadas y la resolución negativa del Consejo Regional del Medio Ambiente (COREMA) de la Región de Antofagasta, para la captación de aguas subterráneas en el sector altoandino de Pampa Colorada ${ }^{5}$. Pero, no siempre y en todo momento las comunidades indígenas han logrado detener trabajos e inscripciones de aguas subterráneas.

Contando con una definición de las tierras indígenas y sus recursos las organizaciones atacameñas y quechuas legalmente constituidas (la Comunidad Indígena) dispusieron de definiciones e información esenciales para formular demandas de titulación de tierras comunitarias y, con ello, de los recursos contenidos allí, como áreas de pastizales, vegas, sectores con leña, lugares con materiales de construcción, etc. Se partió formulando una demanda de titulación de tres millones de ha, considerando prácticamente toda la superficie de la Provincia de El Loa. El Ministerio de Bienes Nacionales y CONADI, en acuerdo con las organizaciones, bajaron esta pretensión a 905.000 ha, correspondientes a áreas de ocupación efectiva demostrable, histórica y actual, de 19 comunidades Indígenas 6 . Traspuesta una década y media de trabajos, las transferencias de tierras llegaban en 2013 a 346.778,21 ha. Es decir, un $38,3 \%$ de lo demandado. Los requerimientos de 
titulación ante las agencias públicas competentes permanecen y han continuado algunos traspasos ${ }^{7}$.

A diferencia del caso aymara, con una extensiva y temprana titulación de tierras de pastoreo $^{8}$, y del mapuche en el sur de Chile (reasentados compulsivamente en "reducciones"), todo ello realizado entre finales del siglo XIX y primeras décadas del siglo XX, en la región atacameña no se entregaron títulos por tierras de pastoreo, nunca se previó hacerlo y tampoco hubo requerimientos al Estado, salvo como iniciativas puntuales. De ahí que las demandas colectivas atacameñas recientes estén tan centradas en los terrenos comunales. No solo como un problema heredado del pasado, sino que también respecto de representaciones de futuro. Una fundada percepción conecta territorialidad indígena, autonomía y continuidad sociocultural. Este proyecto puede sustentarse sobre tierras propias donde, además del dominio material histórico de ellas, también exista la certidumbre jurídica entregada por títulos entregados por el Estado.

Se tiene en los últimos años, entonces, transferencias de tierras entregadas a las comunidades sobre la base de la ocupación efectiva y la histórica demostrable (algo más de un tercio de lo demandado) y tierras con demandas de titulación al Estado de Chile por el restante. La demanda máxima de tres millones de ha se habría transformado en un recurso retórico y no se percibe por ahora como una ambición alcanzable. Pero, el dominio reconocido legalmente y las pretensiones de dominio de las comunidades sobre tierras no tituladas se constituyen en un ámbito de controversia, reivindicación y disputas. Como era posible suponer, no solo con las autoridades y agencias públicas, sino con terceros no indígenas (empresas mineras, titulares de pertenencias mineras, empresarios y empresas que han explorado aguas, hoteles y agentes turísticos, agencias científicas ${ }^{9}$ ) y entre indígenas (al interior de las comunidades por el uso de recursos; pero también entre comunidades por superposición de tierras demandadas).

El Salar de Atacama y áreas cercanas que forman parte de la jurisdicción del municipio de San Pedro de Atacama contienen un área silvestre protegida de considerable importancia biológica y de conservación de la naturaleza. La Reserva Nacional Los Flamencos fue creada en 1990, reúne siete sectores discontinuos y suma 73.986,5 ha ${ }^{10}$. El decreto de creación señala explícitamente en su artículo quinto que no impide labores mineras, pero sí recomienda resguardos ambientales adicionales. Los sectores Soncor y Aguas de Quelana son vecinos a las explotaciones mineras, todos en la base del salar. Aunque no se ha planteado un conflicto directo entre empresas y la Corporación Nacional Forestal (CONAF) ${ }^{11}$, esta agencia pública ha manifestado con claridad su preocupación acerca de la estabilidad del sistema hidrológico del salar, como consecuencia del volumen de extracción de salmueras autorizadas, y en aumento como hemos visto, a Rockwood Lithium y SQM. Además, la laguna de Chaxa en el sector Soncor está concesionada desde 2002 a la Comunidad Indígena de Toconao para la observación de paisaje y avifauna del salar por turistas. Desde el interés por un turismo de paisajes extremos y conservación de la naturaleza, las comunidades atacameñas elaboraron y han generalizado argumentos medio ambientales y económicos contra los daños que estaría provocando la minería del salar, que se suman a las reclamaciones territoriales comunitarias y étnicas.

Una apreciación de conjunto sobre los resultados de las titulaciones de tierras a las comunidades indica que, primero, abarcan una proporción menor a la mitad de las tierras demandadas, aunque sí envuelven y protegen cursos de aguas superficiales importantes; $y$, segundo, excluyen las concesiones y pertenencias mineras que explotan SQM y Rockwood en el área meridional del salar. Excluyen también la concesión científica CONICYT (Comisión Nacional de Investigación), los sectores de la Reserva Natural Los Flamencos, los sitios Ramsar y las concesiones turísticas (entregadas por la CONAF y el MBN). También evitan considerar las pertenencias mineras no explotadas que se encuentran en la base del salar; precisamente aquellas con mayor potencial de explotación económica rentable de sales.

Respecto de las pertenencias mineras y la ocupación del salar por las empresas mineras, la presencia de empresas en su borde oriental ha traído molestias y reclamos. Los dirigentes de base y los pronunciamientos escritos de Peine, Socaire y Toconao durante los procesos de calificación ambiental de proyectos (ampliaciones, innovaciones en procesos productivos) a través de Declaraciones (DIA) o Estudios de Impacto Ambiental (EIA), reiteran ese disgusto y a veces enojo abierto. El borde oriental corresponde a sectores de pastoreo estacional en años lluviosos de algunos pastores de Toconao, Camar, Talabre, Socaire y Peine, mismos sitios en los que se encuentran pozos de agua dulce, ductos, campamentos y otras instalaciones, además de pertenencias mineras de SQM y Rockwood. Ello no afecta extensiones mayores de tierras tituladas, pero sí algunas social y culturalmente significativas ${ }^{12}$. Sí considera superficies más importantes de las tierras que todavía se mantienen en la condición de no transferidas y reclamadas. Asimismo, bajo la convicción de que el Salar de Atacama pertenece a los indígenas atacameños y a sus comunidades se discute, siguiendo un enfoque de reivindicaciones más amplio, 
la legitimidad de los derechos sobre las pertenencias mineras, concesiones de explotación, áreas de faena minera, extracciones de salmueras ricas en sales y litio e instalaciones de las empresas en el salar.

Las organizaciones de representación de segundo nivel, como el Consejo Directivo de la ADI ${ }^{13}$, el Consejero Atacameño ante el Consejo Nacional de la CONADI ${ }^{14}$ y una asociación como el Consejo de Pueblos Atacameños, consiguen aglutinar en órganos de representación común las distintas comunidades indígenas que integran el pueblo atacameño (y quechua). Las ADI no tienen como objetivo atender centralmente las demandas territoriales de las comunidades, ya que aquellas son ante todo un instrumento de coordinación público-indígena de desarrollo, pero como en ellas convergen autoridades provinciales y regionales (en su momento también presencia de algunas empresas), los temas relativos a las demandas territoriales, así como los problemas y conflictos con la minería del salar encuentran aquí una buena tribuna de expresión y de consecución de apoyos (Avendaño 2009). A su vez, el Consejo de Pueblos Atacameños, bajo la fórmula legal de Asociación Indígena, integra los máximos dirigentes de las comunidades indígenas atacameñas ${ }^{15}$, pero no reemplaza el accionar de cada una de ellas -o de un grupo de ellas- en aquellas materias que son de su particular incumbencia. No siempre asuntos que envuelven al conjunto de las comunidades es tomado por esta asociación. Tampoco reemplaza al Consejo Directivo de las ADI, ni lo integra oficialmente, aunque como organización de representación puede tener influencia en las agendas de trabajo que las comunidades promueven en el Consejo Directivo de ADI. La relación con el Consejero Nacional Atacameño también es variable.

\section{Escenarios Locales de Negociación y Conflicto: Comunidades Atacameñas y las Empresas Mineras en el Salar de Atacama}

Los habitantes indígenas de las agrupaciones atacameñas locales, al igual que las organizaciones que ellas sostienen, y las empresas mineras que explotan sales y litio en el Salar de Atacama mantienen profusas relaciones desde el inicio de la minería de salares. La más antigua es una laboral de articulación entre empresas en la minería del salar y la fuerza de trabajo indígena de la zona. Desde el inicio de las actividades extractivas se contrató mano de obra de las comunidades campesinas cercanas al salar (Peine, Socaire, Camar y Toconao), sin que represente una mayoría y principalmente como mano de obra no especializada; es decir, empleos que demandan poca calificación y de los que, en consecuencia, se obtienen bajas remuneraciones. Las empresas mineras también establecieron campamentos dormitorio y de administración en Peine (Sociedad Chilena del
Litio, luego Rockwood Lithium) y Toconao (Sociedad Minera Salar de Atacama Ltda., MINSAL, luego SQM). En los primeros acercamientos entre empresas y población local (1985-1995) aquellas siempre fueron, y siguen siendo, requeridas para ofrecer contratos de trabajo a la mano de obra local. A su vez, las empresas siempre han señalado su disposición, al menos formal, para incorporar trabajadores locales. Existió al respecto un acuerdo entre las comunidades del sector sur del salar y MINSAL, la empresa mixta público-privada que precedió a SQM. Esta última señaló su disposición a mantener ese acuerdo cuando se instaló en el salar. Pero ello se ha materializado con dificultades. La empresa señala que han despedido trabajadores indígenas por incumplimiento de prácticas de seguridad, alcoholismo e inasistencias sin justificación. Reconocen también que la organización del trabajo en el salar con grupos o cuadrillas a cargo de jefes que actúan con "su gente" ha desplazado a trabajadores locales. Por el lado de las comunidades se han producido quejas respecto de la libertad con que jefes operativos imponen su personal y perjudican a los trabajadores atacameños.

Es notoria la ausencia de participación atacameña en los sindicatos de las empresas del litio cuando estos existen; $y$, según se señala, habría en las faenas mineras del salar poca o débil contestación, rechazo o conflictividad de los trabajadores indígenas considerados individualmente. Algunos indicios señalan una relación entre el abandono de posiciones de pasividad ante las condiciones de trabajo en el salar y el surgimiento de demandas y conflictos entre comunidades y empresas mineras. Las comunidades piden y presionan por puestos de trabajo y mejores condiciones laborales para sus trabajadores como parte de sus demandas a las empresas; los trabajadores indígenas en esas empresas plantean solicitudes y reclamos por mejoras en las condiciones de trabajo, en sintonía con los requerimientos de sus comunidades (cupos de trabajo para sus integrantes). A veces, también con el apoyo de sindicatos (por ejemplo, facilidades de transporte entre las comunidades y las faenas mineras en un caso conocido) ${ }^{16}$.

Otra dimensión de las relaciones es la que se da entre empresas mineras y comunidades atacameñas. Atendiendo a la cobertura, algunas de ellas pueden calificarse de locales, en tanto que otras adquieren alcances más amplios. Desde la década del 2000 con más claridad esta relación con la minería del salar se tiñe y reformula desde un discurso étnico, tanto si el objeto inmediato es un asunto local o más general. El carácter de ellas puede ser de cooperación, contestación o conflicto. A su vez, el contenido de las demandas es también diverso:

(a) Territoriales, cuando se sostiene que las áreas de explotación y sitios de faenas e instalaciones de las empresas, así como caminos de tránsito corresponden 
a tierras sujetas a demandas de titulación por parte del Estado, o cuando se señala que los atacameños y cada comunidad en particular tiene derechos sobre los recursos del suelo (canteras, sitios de extracción de leña, medicinas, materiales de construcción) y del subsuelo (sus riquezas minerales).

(b) Ambientales, en la medida que se protesta y se exige por medidas de mayor control y limitaciones a la extracción de aguas subterráneas y salmueras en la cuenca, así como acciones tendientes a resolver efectos negativos sobre agua, flora y fauna del salar y sectores aledaños, imputables a la minería. Suele mencionarse, también, que los atacameños explotaban tradicionalmente algunos recursos en el salar y que las actividades mineras han terminado de interrumpir eso. Otro tanto con el uso turístico del salar, iniciativa en la que ellos son partícipes ${ }^{17}$. La contigüidad de las faenas mineras con la explotación turística del salar, dependiente de una buena conservación, es materia de continua preocupación, a lo que se suma el solapamiento de usos territoriales atacameños históricos.

(c) Culturales, referido al resguardo, limitación de acceso y control sobre sitios de importancia cultural $\mathrm{y}$ aquellos hoy considerados patrimoniales, como senderos de uso histórico, "camino del Inca", sitios arqueológicos, construcciones históricas antiguas en los pueblos, corrales y canchas de cosecha, sitios de faenas tradicionales, lugares rituales.

(d) De desarrollo local, dirigidas a obtener financiamiento de infraestructura y servicios para las localidades interesadas, con mayor o menor participación comunitaria, relación con el gobierno local y otras agencias públicas. Es una de las demandas más persistentes de las comunidades a las empresas.

(e) Asistenciales, definidas como apoyos específicos que puedan tener las comunidades particulares o grupos dentro de ellas, no sujetos a una lógica de definición y desarrollo de proyectos (p.ej., el préstamo de un equipo electrógeno para resolver problemas de iluminación y disposición de energía con ocasión de festividades y reuniones sociales).

(f) Sociales, como cuando se ha pedido reglamentar en los centros poblados las relaciones entre los trabajadores de las empresas y los residentes atacameños, solicitando a los primeros que sigan un cierto protocolo de conducta que no altere la vida cotidiana de las aldeas y de sus moradores; en particular de mujeres jóvenes.

(g) Por último, financieras o de transferencia directa, como un fenómeno emergente en el que comunidades u organizaciones de comunidades están negociando fondos de dinero administrados por ellas mismas en función de sus objetivos y necesidades (financiación de proyectos, de asesoría especializada, gastos de dirigentes, dietas mensuales para dirigentes y representantes, etc.).

Una comunidad puede simultánea o sucesivamente sostener o transitar por los distintos tipos de requerimientos y demandas, con uno y otro carácter, según las circunstancias y momentos. Y esto vale para las empresas mineras, como también, con alcances más limitados, para aquellas subcontratistas mandatadas por las anteriores. Los casos de Peine, Socaire y Toconao atestiguan que un ciclo de relaciones marcado por el conflicto puede abrir paso a acuerdos de desarrollo local, o a una serie de acciones asistenciales y de nuevo escalar a tensiones y problemas. No obstante, una visualización de conjunto para el periodo muestra que unas han surgido primero y otras después, siendo aquellas financieras o de transferencia directa las de más reciente generación, y las asistenciales, más tradicionales, y aquellas con las que de todas maneras siempre se cuenta.

Por el lado de las empresas, varias son las formas características en que se han elaborado relaciones con las comunidades y poblados que se encuentran en el área de influencia de sus proyectos. Es pertinente llamarlas paradigmas de relación, pues corresponden a concepciones de empresa y, como parte de ello, un modo de concebir los vínculos con el contexto donde se insertan (medio ambiente, territorios, agencias públicas, actores sociales, económicos y políticos). El asistencialismo es para nuestros propósitos un primer paradigma de relaciones comunidad-empresa en el salar. Podemos definirlo como un tipo de relación al que se le da un carácter voluntario y, con apariencia de desinteresado, expresivo de generosidad, altruismo y filantropía, ya que no depende de compromisos contractuales o acuerdos formales sostenidos en el tiempo entre la empresa y beneficiarios locales. Es acotado ya que se agota en actos definidos de entrega o traspaso de bienes o servicios solicitados expresamente para resolver situaciones específicas de un grupo o toda la localidad. Por realizarse entre sujetos situados en posiciones de manifiesta desigualdad, se parece demasiado a la caridad como para no considerarlo un modo de relación empresarial con la pobreza que ha sido característico en Chile. Fue la modalidad prevaleciente de relación de las empresas del litio con las comunidades vecinas hasta bien avanzada la década de 1990, periodo en que se hizo necesario crear unidades de trabajo para la sostenibilidad ambiental, en los albores del surgimiento de actores comunitarios y hasta en tanto no se definieron demandas territoriales y se buscó ejercer los derechos invocados. Aunque este tipo de práctica sigue vigente, cambios internacionales de las concepciones de empresa y sus responsabilidades con la sociedad, la legislación indígena, la ambiental, 
las agencias públicas y las propias comunidades apoyándose en los nuevos marcos legales, empujaron a las empresas hacia nuevos términos de relación.

Un segundo paradigma de relaciones innova en cuanto plantea la acción hacia la comunidad bajo un esquema de política empresarial y no, simplemente, reaccionando a solicitaciones diversas y esporádicas desde el entorno. Debe entenderse como el interés por una acción estructurada y de más largo plazo, en función de mostrar hacia afuera los esfuerzos que realiza una empresa para tener en cuenta la población $\mathrm{y}$ hacerla participar en proyectos de alcance local. $\mathrm{Y}$ esto se inscribe en la incorporación de nociones de Responsabilidad Social Empresarial (RSE) que empiezan a adoptarse en Chile como marco de estructuración de las relaciones empresariales con el entorno en la década de 1990. La redefinición de relaciones definidas por el asistencialismo logra importancia, igualmente, a medida que cambia el contexto político inmediato de la minería del salar (formación de actores colectivos organizados, democratización del gobierno local en la década de 1990), en el nacional (política indígena y política ambiental como lo más relevante) y el internacional (Responsabilidad Social Empresarial y, más recientemente, el principio de "valores compartidos", esto último vinculado al paradigma de la minería sustentable). De esa manera, ante la formación de actores indígenas, las empresas (en particular SQM) se vieron forzadas a estructurar acciones más regulares, planificados y en sintonía con algunas demandas locales. Otro tanto ocurrió cuando para obtener permisos ambientales derivados de una legislación que va planteando mayores exigencias, las empresas del Salar de Atacama establecen compromisos de compensación y mitigación. Ellos se traducen en cursos de acción que, en lo tocante a las comunidades, se organizaron como un programa de desarrollo local.

En consecuencia, las empresas mineras del salar han sido hasta muy recientemente más reactivas que propositivas en materia de relaciones comunitarias. Se llega al extremo de que hasta un momento tan tardío como el año 2013 Rockwood Lithium no tenía una unidad de trabajo ambiental incorporada a la planta de la empresa. Los requerimientos en esta materia se externalizaron con el concurso de profesionales y empresas consultoras ambientales. $\mathrm{Y}$ las relaciones con las comunidades, Peine y Socaire especialmente, las realizaba directamente el gerente de producción en el norte del país. A su vez, con la puesta en marcha de las exigencias de evaluación de impacto ambiental -Estudios de Impacto Ambiental y Declaraciones de Impacto Ambiental, SQM creó en sus divisiones unidades ambientales con el rango de gerencias. Cuando a esta legislación se agregan exigencias de participación, ya desde mediados de la década del 2000 se incluyen científicos sociales (p.ej., sociólogos) y se organiza un plan de desarrollo local enfocado a un trabajo con el municipio (en educación) y algunas comunidades indígenas (en agricultura, microproyectos económicos y proyectos cultural patrimoniales) ${ }^{18}$.

Los tipos de relación presentados hicieron crisis en las comunidades atacameñas en la segunda mitad de la década del 2000, periodo en que se produjeron varios hechos relevantes. El primero es la oposición y conflicto que mantuvo durante 2005 y 2006 SQM Salar con algunas comunidades para la ampliación de las faenas mineras y extracción de salmueras en el Salar de Atacama ${ }^{19}$. Un segundo hito se abre en 2007 con el inicio de un EIA para un proyecto de exploración geotérmica en el campo de geiseres de El Tatio que, luego de su socialmente resistida gestión y aprobación en 2008, concluye en 2010 con la suspensión indefinida del proyecto, luego de la falla en un pozo de exploración y de comprobarse diversas infracciones en su ejecución. Un tercer acontecimiento relevante también se produce en 2007 con el EIA "Suministro de Agua Pampa Colorada" presentado por la Empresa Minera La Escondida (EMEL). Las comunidades que se sentían afectadas (Peine, Socaire principalmente, a las que se suma Toconao) y el gobierno local de San Pedro de Atacama se opusieron a La Escondida por la extracción de aguas subterráneas en el sector altoandino de Pampa Colorada. Se suman luego otras organizaciones y personas atacameñas, así como activistas locales y regionales del medio ambiente. Otro hecho relevante es el que tiene lugar el año siguiente, con la suscripción por parte de Chile del Convenio 169 de la OIT (Organización Internacional del Trabajo), un compromiso estatal que las organizaciones indígenas del país venían reclamando cumplir desde el primer gobierno del retorno a la democracia en 1990.

Los desenlaces con resultados variables en favor de los proyectos de inversión minera o geotermia, o en favor de las comunidades y organizaciones opositoras, tienen a nuestro entender un doble resultado para las relaciones futuras entre comunidades indígenas y empresas mineras del Salar de Atacama. Por una parte, se extiende la percepción entre los actores indígenas de la zona que los proyectos de inversión en territorios indígenas (tierras propias y demandadas, ADI, municipios con gobiernos indígenas) deben establecer términos de relación muy distintos a los que venían sosteniendo históricamente. Por otra, las empresas interesadas en impulsar inversiones en esas zonas parecen convencerse que el escenario de actores y relaciones en las áreas de 
minería y energía en áreas indígenas ha cambiado sin retorno. En esta medida, asistimos a un giro y cambio de dirección en los términos de estos vínculos y, en tal caso, al surgimiento de un nuevo paradigma de relaciones.

Una tercera configuración de relaciones se abre paso, el paradigma de los valores compartidos, en la que la articulación y el trabajo de relacionamiento no se hacen a través de proyectos orientados por las prioridades de la empresa, sino que considera la participación y el desarrollo local y socio organizativo autónomo. Es imaginable que en las prácticas concretas de relación empresa-comunidad se den combinaciones de las tres modalidades, pero según la empresa y periodo que se analice prevalece uno y más tarde otro. Señalemos que cabe en la definición de "valores compartidos" el modelo de minería sustentable que suscribe el International Council on Mining \& Metals (ICMM), del cual participan todas las grandes compañías mineras internacionales con presencia en Chile y las asociaciones nacionales de empresas en la minería. La noción de valor compartido se ha erigido entonces como una nueva concepción de empresa en que la RSE y la filantropía que todavía se encuentra en su base, son reemplazadas por el principio de que el valor económico para la empresa y el valor social para las comunidades del entorno quedan integrados en una misma estrategia corporativa, en la que ocupan un lugar relevante el interés o valoración de las necesidades de comunidades y empresas que le sirven de contexto, transformaciones en el diseño de sistemas operativos y la creación de nuevos productos y servicios entendidos como oportunidades para la empresa. En la práctica ello puede tener mucho de retórico.

Su aplicación al contexto atacameño del Salar de Atacama puede caracterizarse como la búsqueda de licencia social comunitaria asociada a compromisos, principalmente económicos, de mucha más envergadura que en el caso de las fórmulas arriba descritas. Se plantea como un vínculo de asociatividad participativo que otorga considerable autonomía a las comunidades o agrupación de comunidades en las decisiones de uso de tales recursos financieros o materiales. Hasta ahora se ha ensayado por parte de empresas que operan en el área meridional de las comunidades atacameñas del salar (Minera Escondida de BHP Billiton), mediante la creación de un fondo de desarrollo local autogestionado para Peine, y acuerdos de transferencias directa a la comunidad de Peine ${ }^{20}$ por parte de Rockwood Lithium y a cada una de las comunidades integrantes del Consejo de Pueblos Atacameños y a la propia asociación indígena Consejo de Pueblos ${ }^{21}$. Como hemos recalcado, SQM sostiene hasta ahora un modelo de programa de desarrollo local por proyectos más conservador, clasificable dentro de los esquemas más clásicos de una definición de Responsabilidad Social Empresarial ${ }^{22}$.

La participación local y sus alcances posiblemente sea el asunto en el que más ambigüedad permanece en el esquema de relaciones de valores compartidos. Las empresas citadas conceden márgenes de decisión para que las propias agrupaciones atacameñas (comunitarias o más amplias) establezcan usos y prioridades de uso para transferencias económicas que se han convenido con ellas. En esa medida, se trata de componentes de relación emergentes considerablemente menos asimétricos entre empresas y comunidades. No obstante, persiste incertidumbre en las grandes empresas de la minería en Chile, según se desprende de comentarios y aprehensiones de personeros consultados, acerca de cómo se puede ejecutar concretamente en las áreas de impacto e influencia directa de sus faenas. Por otra parte, las empresas mineras esperan de las comunidades una recepción favorable a su permanencia, desarrollo y continuidad de concesiones de explotación o ampliaciones de faenas (licencia social). Pero, esto no es seguro que se conciba de la misma manera por las comunidades en cuanto a la continuidad de la licencia social, como a la cuantía de los recursos económicos transferidos y al origen de estas provisiones (fondos sociales, o de otro tipo como la participación de utilidades). Es decidor al respecto el informe que agregó el Consejo de Pueblos Atacameños al grupo de trabajo encargado de la formulación de orientaciones de política para el litio, organizado por mandato presidencial en el Ministerio de Minería durante 2015.

Rockwood Lithium, controlado ahora por Albemarle, ejemplifica una transformación dramática de la concepción y prácticas de relación con las agencias públicas nacionales (Ministerio de Minería, CORFO, Servicio de Evaluación Ambiental) y el entorno local (comunidades, organizaciones de segundo nivel, gobierno municipal) en el Salar de Atacama. Acuciados por la necesidad de asegurar la continuidad de la concesión de explotación de las pertenencias de $\mathrm{CORFO}^{23}$, ampliar esta misma concesión, mejorar su posición en el mercado global del litio de salmueras respecto de SQM, crear condiciones adecuadas para futuros permisos ambientales y licencias sociales, mediante una revisión de los contratos y la búsqueda de una nueva forma de relación con los actores locales indígenas, la empresa está haciendo un importante esfuerzo por construir un posicionamiento expansivo y, a la vez, equilibrado y sustentable en la minería del litio. Es notorio el interés en dar forma a una imagen local positiva, luego de los traspiés vividos con el intento de "saneamiento ambiental" de sus actividades 
extractivas del salar en años reciente ${ }^{24}$, e intenta lograr una imagen favorable ante las agencias estatales que evalúan los efectos medio ambientales y sociales de sus faenas actuales y las proyectadas. Visto de manera más general, a ella le interesa mantener la producción de litio de salmuera por sus costos y por seguridad de abastecimiento. Por tratarse de una empresa con actividades en diversos puntos del planeta, también se trata de mostrar una visión favorable, en función de consecuencias de mercado, financieras y político empresariales de signo positivo.

La fórmula que preside esta innovación en la relación de la empresa con las comunidades indígenas del área de influencia próxima es la participación de beneficios, en el sentido que define la perspectiva de los "valores compartidos" (compartir ganancias y entregar beneficios a las comunidades y organizaciones indígenas demandantes o enfrentadas con Rockwood Lithium por el dominio del salar y las sales del subsuelo). En segundo término, se trata de un compartir mediante transferencias financieras directas acordadas con organizaciones. Mismas que dirigen esos recursos a una agenda de acciones propia. Y, en tercer lugar, se trata de compartir valores en un horizonte de tiempo amplio. Se busca en esa medida conseguir acuerdos estables. Ello representa una novedad, ya que el tipo de acción precedente fue el de un asistencialismo informal y un programa convencional de proyectos de desarrollo local; este último es el caso de SQM desde una óptica de Responsabilidad Social Empresarial.

La fórmula ensayada tiene indudable novedad y atractivos. Es una respuesta consistente con la crítica que normalmente se le endosa a los proyectos mineros de que sacan riqueza de las localidades y dejan solo poco más que deterioro ambiental, relaves, residuos y costos sociales derivados del término de actividades, en una economía local que se fue adecuando, en diverso grado, a las oportunidades y posibilidades que ofreció ${ }^{25}$. A diferencia de las fórmulas convencionales de relación, otorga considerable autonomía a las comunidades y sus organizaciones en la definición y ejecución del desarrollo local y, en esa medida, facilita su conformación como agentes centrales de su desarrollo. Representa a nuestro entender un mecanismo eficiente para destrabar problemas y bloqueos que se vivieron durante años recientes en las relaciones entre comunidades atacameñas, organizaciones de segundo nivel y empresas. Las dinámicas que ello estaría generando son todavía poco visibles; en cualquier caso, resulta notorio que bajo estos términos se hace más ambiguo identificar y perfilar la condición de adversario en una lógica de dicotomización (aliado/adversario, amigo/enemigo, buenos/malos).
La negociación de la distribución de recursos y las decisiones de financiamiento son ahora internas. Ya no se expone, como en el caso de un sistema de proyectos trazado externamente, a ser evaluado como excluyente de partes de la comunidad y los costos de esas decisiones se trasladan de afuera a adentro. En esa medida disminuyen riesgos de transacción y respecto de sus resultados ${ }^{26}$. Para las comunidades y organizaciones resulta una fórmula atractiva, vista como una respuesta afirmativa y favorable a sus demandas. Goza de la percepción de ser un mecanismo de relación mucho más horizontal y respetuosa de la comunidad, sus intereses y deseos. Claramente se gana legitimidad en la relación de las empresas con las comunidades.

\section{Reflexiones Finales}

El litio cobra visibilidad mundial por su condición de materia prima para la transición hacia tecnologías más sustentables. Este interés ha puesto en la retina global el "triángulo del litio". Pero el interés, notoriedad y expectativas creadas alrededor de este especial mineral tiende a restar visibilidad a las insustentabilidades que arrastra. La llegada de las empresas del litio al Salar de Atacama fue inicialmente bien valorada por las oportunidades de empleo abiertas y el acceso a algunos servicios, además de donaciones y ayudas. Con el paso de los años esa visión y relaciones se han transformado progresivamente. Se han diferenciado para cubrir una mayor diversidad de vínculos: individuales (laborales, de ayuda social a trabajadores y familias) y colectivas (acuerdos de cooperación, pero también controversias, disputas y conflictos). Otro tanto con las percepciones y juicios, en que la valoración inicial de las ventajas abiertas por su presencia ha dado paso, sin reemplazarla del todo, a las demandas de reconocimiento de derechos, requerimientos de distribución de beneficios y, relacionado con esto, el cuestionamiento por los costos e impactos ambientales y socioculturales que sus actividades generan.

Lo primero remite a la posición de organizaciones y líderes atacameños sobre derechos territoriales que exigen se les sean respetados. Por las empresas mineras, pero también por otros proyectos, como el territorio cedido a la agencia científica chilena CONICYT, ocupado por el proyecto astronómico ALMA y otros. Lo segundo se refiere los beneficios económicos que la minería en el salar reporta a las empresas por relación con los menguados retornos que llegan a la población local: salarios bajos, ayudas y transferencias limitadas, apoyos modestos al desarrollo de las comunidades cercanas, o al municipio. Más aún, con la convicción actual que el 
Salar de Atacama pertenece a los atacameños y sus comunidades. Lo tercero, a que la minería de salares produce efectos ambientales negativos por la sobre explotación de aguas, los efectos nocivos sobre flora y fauna, al igual que la alteración de paisajes debido a sus faenas, instalaciones, funcionamiento y desechos. Perciben también que la vida local ha estado cambiando irreversiblemente, con actividades agropecuarias más bien testimoniales, dependencia de ingresos salariales, nuevos patrones de consumo y otros proyectos de vida. A esta altura, la distancia -o añoranza- con las formas de vida de sus padres y abuelos es atribuida en parte a la presencia e influencia de las empresas mineras en el salar. Las propias empresas también han transformado, con ritmos y fórmulas distintas una de otra, la relación y perspectivas que mantienen con el entorno social atacameño; en parte para ajustarse a cambios en la legislación nacional y a los estándares internacionales de relación con las comunidades en sus áreas de influencia; en parte para reaccionar a la constitución de actores y demandas locales nuevas.

Las empresas mineras inician sus actividades en el Salar de Atacama, una a mediados de la década de 1980 , y la otra a mitad de la década siguiente aunque con una rápida expansión. La conformación de actores y demandas étnicas es algo posterior. Son años, entonces, en que se dan relaciones comunidades - empresas en el ámbito del trabajo y prestaciones basadas en criterios de "buena vecindad" de estas hacia las primeras y el municipio de San Pedro de Atacama. Con la concurrencia de nuevos procesos y actores (estatales, globales, locales, étnicos) empieza a darse un cuadro de relaciones mucho más variado, tensionado y en transformación. Es en el interjuego de las relaciones entre comunidades y empresas junto a factores externos que este nuevo esquema adquiere fisonomía. Sus elementos principales, como fuimos presentando, son las siguientes. Primero, la formación de demandas territoriales comunitarias y étnicas en Atacama. Desde principios de la década de 2000 se presionó a las agencias y organismos públicos la titulación de extensos territorios de ocupación histórica de cada comunidad. Las organizaciones y representación de segundo nivel (Consejo de Pueblos Atacameños, directorio de ADI, Consejero Atacameño en CONADI) pugnaron por hacer avanzar las decisiones de titulación a todo el espacio étnico. El gobierno comunal también solidarizó con estas demandas. Los resultados han sido modestos. Así y todo, permitió que, en lo sucesivo, tanto las tierras demandadas por las comunidades, como las entregadas en dominio y tituladas dentro de ellas, representen la base de las oposiciones y reclamaciones hacia las empresas que explotan el salar de Atacama, que captan aguas subterráneas en la zona, que poseen extensas pertenencias mineras y que mantienen instalaciones y faenas. Lo hacen no solo respecto de las tierras, las aguas corrientes y bienes usados históricamente por los pobladores atacameños, sino que también los recursos del subsuelo, las aguas subterráneas, la flora y la fauna, el paisaje de salares y montañas, la sostenibilidad de todo ello amenazado por la sobreexplotación, la intervención por caminos, ductos y faenas, o la contaminación.

Asimismo, desde 1997 empieza a operar el reglamento de la tramitación ambiental (de la Ley 19.300 de Bases Generales del Medio Ambiente de 1994) que se debe considerar para realizar ampliaciones y nuevos procesos con litio y potasio, que hizo exigible entrega de información, consultas y una recomendación de atender las observaciones de las comunidades correspondientes a las áreas de influencia de los nuevos proyectos. Además, en 2008 se aprueba el Convenio 169 de la OIT que plantea criterios de información y consulta indígena más elevados que cualquier otro cuerpo legal. Todavía, la Ley $\mathrm{N}^{\circ} 20.417$ de 2010 la reforma $\mathrm{N}^{\circ} 19.300$, abriendo las opciones para que los afectados y otros interesados -se incluyen personales naturales, jurídicas y organizaciones- puedan formular observaciones y reclamaciones ante la autoridad competente. Pero no se trata solo de condiciones que mejoras legales o nuevas legislaciones imponen en materia de información oportuna, consulta, reclamación y arreglos con el entorno social de los proyectos de inversión. Las propias empresas se han abierto a modelos o paradigmas de relacionamiento, pasando de la filantropía, o así entendida, a la Responsabilidad Social Empresarial, en Chile presente desde la década de 1990, y de ahí a la de Valores Compartidos hoy impulsada oficialmente, con notoriedad en la minería y recomendada para el caso de la explotación de litio y potasio en el Salar de Atacama. Podemos sugerir que es la propiedad estatal de las pertenencias mineras del salar la que permite al Ministerio de Minería hacer planteamientos tan directos; en otras circunstancias el tono sería más atenuado. De esta manera, en los nuevos términos de relación a los que las empresas se abren, impuestas por la legislación ambiental o la indígena, concurren principios de ética empresarial, regulaciones nacionales, pero también exigencias internacionales de certificación cuando, como en la minería de salares, se produce para mercados globales en que estos temas son sensibles y requieren atención para desenvolverse allí.

Lo anterior obligó a las empresas de la minería del Salar de Atacama a establecer canales de información y consulta y a crear unidades de relación con comunidades. En el caso de Rockwood más tardíamente que SQM, al amparo de la tranquilidad que gozó hasta inicios de la presente década con su esquema paternalista de asistencia. Aunque quizá 
también por su relativamente menor tamaño y el efecto de sombra (atenuación de visibilidad) que SQM y sus proyectos de ampliación ejercieron sobre ella. Derechos territoriales comunitarios y no solamente tierras de uso actual son invocados por las comunidades indígenas ante las empresas mineras y otros agentes económicos (empresas de exploración de aguas, proyectos públicos de caminos y carreteras, por ejemplo). Las empresas se encuentran amparadas por la legislación minera, inscripciones vigentes sobre el subsuelo y disponen de permisos ambientales. Pero, con cada nuevo proyecto que emprenden (ampliaciones, nuevos procesos), deben gestionar permisos ambientales en los que se ven obligados a informar, consultar y buscar acuerdos bajo un enfoque de responsabilidad social empresarial o de valores compartidos. Es en esas coyunturas que los actores locales, comunitarios y étnicos adquieren fuerza y poder, negándose a buscar puntos de convergencia, abriéndose a un diálogo trabajoso y dilatado en el tiempo y/o avanzando en los límites de la base de acuerdos existente con ellos o en la zona. El mejor ejemplo es el arreglo de participación de las ventas de litio y potasio que las comunidades indígenas, el Consejo de Pueblos Atacameños de San Pedro de Atacama y Rockwood Albemarle alcanzaron el año 2016. Pero, tampoco cabe engañarse. La empresa estaba empeñada en una audaz negociación con CORFO, exitosa a la postre, para expandir fuertemente sus actividades en la producción de litio y su elaboración en Chile. El inédito convenio logrado con las comunidades debe entonces situarse como parte de una ambiciosa estrategia empresarial.

Consideramos necesario abandonar la imagen de resistencia y conflicto continuo y persistente entre comunidades indígenas y empresas de la minería de sales en el Salar de Atacama o de cobre en sus inmediaciones. Por el contrario, conviene prestar atención a un doble movimiento cuyos lineamientos principales intentamos más arriba trazar. Por una parte, la alternancia de momentos o coyunturas de conflictividad abierta y periodos donde prima el diálogo y los acuerdos $\mathrm{o}$, al menos, demandas y tensiones contenidas. Por otra, el carácter progresivo de las relaciones y los contenidos de ellas entre el momento en que la explotación de sales en el Salar de Atacama adquiere escala industrial en la década de 1980 y el presente, mediado por desarrollos en la legislación indígena y ambiental, la constitución de actores indígenas, la formulación de demandas comunitarias y étnicas y los modelos de vinculación empresarial con su entorno social. La alternancia de momentos y signos más o menos conflictivos o de diálogo y negociación en las relaciones estudiadas adquiere nuevas definiciones con su progresión en la dirección que presentáramos. La primera dinámica no puede, entonces, entenderse sin acudir a la segunda cuando se quiere establecer cambios en los actores, sus formas de acción y el contenido específico de las demandas. Asimismo, el análisis de las relaciones comunidad-empresa en el plano local no es condición suficiente para entender los términos, los contenidos, su variación en el tiempo, recurrencias o desarrollo. Se requiere acudir a una escala nacional, en particular la legislación y sus cambios, la acción de las agencias públicas; y a un plano global, en específico, de acuerdos internacionales suscritos por Chile como el Convenio 169 de la OIT, o los criterios de los consejos mineros a nivel global respecto de los vínculos con el entorno social y natural y su incidencia sobre políticas y normativas en el plano nacional.

Agradecimientos: El presente artículo es el resultado del trabajo conjunto de los autores en el marco del proyecto de investigación Fondecyt Regular N ${ }^{\circ} 1150573$ "Las relaciones interétnicas en Chile, su diversidad regional y cambios recientes", del Fondo Nacional de DesarrolloCientífico y Tecnológico (Fondecyt-Conicyt) de Chile, y la "Red internacional de investigación sobre desigualdades interdependientes en América Latina desigualdades.net" financiada por el Ministerio Alemán de Educación y Ciencias (BMBF). Es resultado, también, del intercambio académico desarrollado por el Proyecto Redes 150126 (Conicyt): "Multidisciplinary Research Network on Mining Systems in the Atacama Desert (IIAM-UIBK)", Chile-Austria. Agradecemos a estas agencias científicas su generoso apoyo. Agradecemos también las observaciones, comentarios y críticas de tres evaluadores de este artículo.

\section{Referencias Citadas}

Avendaño, S. 2009. Áreas de Desarrollo Indígena en el Norte de Chile. Negociaciones y Disputas en Torno a Espacios Territoriales. Tesis de Magister en Ciencias Sociales, Universidad de Chile, Santiago.

Azocar, R. 2015. Pampa Colorada: Conflicto Etno-Ambiental y Movimiento Indígena Atacameño. Tesis de Licenciatura en Antropología, Universidad de Chile, Santiago.

Babidge, S. 2013. Socios: The contested morality of partnerships in indigenous community - mining company relations, northern
Chile. Journal of Latin American and Caribbean Anthropology 18 (2):274-293.

Babidge, S. 2015. Contested value and an ethics of resources: Water, minig and indigenous people in the Atacama Desert, Chile. The Australian Journal of Anthropology. Published online 12, may 2015 doi: 10.1111/taja.12139.

Bolados, P. 2014. Los conflictos etnoambientales de "Pampa Colorada" y "El Tatio" en el Salar de Atacama, norte de Chile. Procesos étnicos en 
un contexto minero y turístico transnacional. Estudios Atacameños. Arqueología y Antropología Surandinas 48:229-248.

Cuadra, M. 2000. Teoría y práctica de los derechos ancestrales de agua de las comunidades atacameñas. Estudios Atacameños 19:93-112.

González, H. y H. Gundermann 1996. Contribución a la Historia de la Propiedad Aymara. Corporación Nacional de Desarrollo Indígena (CONADI), Santiago.

Gundermann, H. 2001 Comunidad, Sociedad Andina y Procesos Socio-Históricos en el Norte de Chile. Tesis Doctoral, El Colegio de México, México D.F.

Gundermann, H. 2013. Los atacameños y sus relaciones interétnicas. En Pueblos Originarios y Sociedad Nacional en Chile. La Interculturalidad en las Prácticas Sociales, editado por J. Durston, pp. 81-97. Programa de las Naciones Unidas para el Desarrollo (PNUD), Santiago.

Gundermann, H., H. González y J. Durston 2018. Interetnicidad y relaciones sociales en el espacio atacameño. Estudios Atacameños. Arqueología y Antropología Surandinas 57 (en prensa).

Gundermann, H. y J. Vergara 2009. Comunidad, organización y complejidad social andinas en el norte de Chile. Estudios Atacameños. Arqueología y Antropología Surandinas 38:107-126.

Morales, H. 2014. Génesis, formación y desarrollo del movimiento atacameño (norte de Chile). Estudios Atacameños. Arqueología y Antropología Surandinas 49:111-128.

Morales, H. y R. Azocar 2015. Minería y relaciones interétnicas en Atacama. Estudios Atacameños. Arqueología y Antropología Surandinas 51:49-63.

\section{Principales documentos consultados}

Comisión Chilena del Cobre (COCHILCO) 2009. Antecedentes para una Política Pública en Minerales Estratégicos: litio. Departamento de Estudios.

Comisión Nacional de Litio 2015. Litio: una fuente de energía, una oportunidad para Chile. Informe Final.

Consejo de Pueblos Atacameños 2015. "Aportes del Consejo de Pueblos Atacameños para la Comisión Nacional del Litio", en anexos al Informe Final de la Comisión Nacional de Litio.

Consejo Regional del Medio Ambiente (COREMA) Región de Antofagasta 2005. Estudio de Impacto Ambiental (EIA) "Cambios y mejoras de la operación minera en el Salar de Atacama" presentado el 10 de enero de 2005 y aprobado el 19 de octubre de 2006, según Resolución de Calificación Ambiental 0226 .

Consejo Regional del Medio Ambiente (COREMA) Región de Antofagasta 2007. Estudio de Impacto Ambiental (EIA) "Perforación Geotérmica Profunda El Tatio, Fase I" presentado en agosto de 2007 y aprobado el 3 de julio de 2008, según Resolución de Calificación Ambiental (RCA) 0229.

Consejo Regional del Medio Ambiente (COREMA) Región de Antofagasta 2007. Estudio de Impacto Ambiental (EIA) del proyecto "Suministro de Agua Pampa Colorada" de Minera Escondida Limitada, ingresado a evaluación el 9 de enero de 2007. Solicitud de calificación ambiental rechazada según Resolución Exenta 0366 del 19 de noviembre de 2007.
Dirección General de Aguas (DGA) y Corporación Nacional de Desarrollo Indígena (CONADI 1997. "Convenio Marco para la protección, constitución y restablecimiento de los derechos de aguas de propiedad ancestral de las comunidades aymaras y atacameñas", suscrito el 30 de mayo de 1997.

European Commission Raw Material Strategy Report 2010 - 2011.

Gobierno de Chile 1993. Ley N¹9.253 Ley Indígena.

Gobierno de Chile 1994. Ley $N^{\circ} 19.300$ de Bases Generales del Medio Ambiente del 9 de marzo de 1994.

Gobierno de Chile 2008. Ratificación Convenio 169 de la OIT del 14 de Octubre de 2008.

Gobierno de Chile 2010. Ley № 20.417 que crea el Ministerio del Medio Ambiente, el Servicio de Evaluación Ambiental y la Superintendencia del M Ambiente, del 12 de enero de 2010.

Ministerio de Agricultura 1990. Decreto $\mathrm{N}^{\circ} 50$ del Ministerio de Agricultura de fecha 2 de abril de 1990 crea Reserva Nacional "Los Flamencos" en terrenos fiscales de la II Región y la declara lugar de interés científicos para efectos mineros.

Ministerio de Bienes Nacionales 1997. Proyecto: "Ordenamiento Catastral de las Comunidades Indígenas del Altiplano de la II Región, Provincia del Loa", solicitado por el Ministerio de Bienes Nacionales, y ejecutado por Consultora CINPRO.

Ministerio de Bienes Nacionales 1998. Proyecto: "Subsidio para la regularización de tierras atacameñas y quechuas de la Provincia de El Loa", Consultora Datura Ltda., mandatada por la Corporación de Desarrollo Indígena (CONADI), según convenio de ejecución de fecha 17 de Diciembre de 1998.

Ministerio de Bienes Nacionales y Corporación Nacional de Desarrollo Iindígea (CONADI) 1994. Acuerdo Marco Ministerio de Bienes Nacionales y Corporación Nacional de Desarrollo Indígena (CONADI), del 11 de agosto de 1994.

Ministerio de Bienes Nacionales y Corporación Nacional de Desarrollo Indígena (CONADI) 1994. "Acuerdo Marco Ministerio de Bienes Nacionales y Corporación Nacional de Desarrollo Indígena (CONADI)", del 11 de agosto de 1994.

Ministerio de Minería 2014. DS N 60 del 11 junio 2014 Crea Comisión Asesora Ministerial denominada "Comisión Nacional del Litio".

Ministerio de Minería 2016. Política del litio y la gobernanza de los salares.

Rockwood Litio Ltda. y Comunidad Indígena de Peine 2012. Convenio de cooperación, sustentabilidad y beneficio mutuo entre comunidad indígena atacameña de Peine y Rockwood Litio Ltda.", firmada el 8 de noviembre de 2012.

Rockwood Litio Ltda., Consejo de Pueblos Atacameños, Comunidad Indígena de Rio Grande y otras 2016. Convenio de cooperación, sustentabilidad y beneficio mutuo entre Consejo de Pueblos Atacameños, Comunidad Indígena Atacameña de Rio Grande y otras y Roockwood Litio Ltda.”, suscrito el 21 de febrero de 2016

Servicio de Evaluación Ambiental 2009. "EIA Modificaciones y mejoramiento del sistema de pozas de evaporación solar en el Salar de Atacama". Ingresado 15 septiembre 2009 y aprobado el 20 de enero de 2016 mediante Resolución Exenta $\mathrm{N}^{\circ} 0021$.

SQM 2014. Reporte SQM Sustentable 2014. 
${ }^{1}$ Hemos incorporado revisiones formales y desarrollos de contenido sugeridos por los evaluadores. Varios temas y cambios propuestos no son posibles de abordar aquí a pesar de su indudable importancia. En parte por razones de extensión ya que por instrucción de los editores se debió reducir el tamaño del documento. En parte porque algunos capítulos del artículo entregan solo información estrictamente necesaria de contextualización.

${ }^{2}$ El artículo no trata la evolución de la empresa durante los últimos dos años, atravesada por una aguda controversia con la Corporación de Fomento (CORFO), un informe de la Cámara de Diputados muy crítico respecto de sus prácticas, su apertura al litio en roca mediante compra de pertenencias mineras en Australia, así como, a última hora, el exitoso -aunque cuestionado- resultado de negociaciones con CORFO. Se trata de un escenario muy dinámico que requiere, lo mismo que para el caso de Rockwood, ahora Albemarle, una indagación por sî misma.

${ }^{3}$ Un análisis pormenorizado de la organización indígena y los procesos de los que forman parte para el norte de Chile se encuentra en Gundermann y Vergara (2009:107-126). Para el caso atacameño puede consultarse también Morales (2014).

${ }^{4}$ Una presentación pormenorizada del proceso de saneamiento y titulación de esas aguas en Cuadra (2000:93-112).

5 Respecto de Pampa Colorada, puede consultarse Azocar, (2015); también Bolados, (2014), Morales y Azocar (2015); referencias a ello en relación con controversias de valoraciones en Babidge, (2015)

${ }^{6}$ Inicialmente 19 , pero 31 al momento de este balance (27 atacameñas, tres quechuas y un aymara).

${ }^{7}$ En 2015 se informa de nuevas entregas de tierras: 35.899,5 ha a Chiu-chiu; 2.018,5 ha a Lasana y 7.399 ha a Toconce, todas comunidades del Alto Loa.

${ }^{8}$ Lo que originó comunidades sucesoriales, cf. González y Gundermann (1996) y Gundermann (2001).

${ }^{9}$ Nos referimos a las reclamaciones interpuestas en 2014 por Toconao, comunidades de los oasis de San Pedro de Atacama y la Municipalidad de San Pedro de Atacama, contra el CONICYT por el parque científico (astronómico) del área Pampa La Bola y cerro Chajnantor y, de paso, contra el proyecto astronómico ALMA, sobre una superficie de 36.281 ha.

${ }^{10}$ Decreto $\mathrm{N}^{\circ} 50$ del Ministerio de Agricultura de fecha 2 de abril de 1990. Varios de los sectores que componen la Reserva son sitios Ramsar de conservación de humedales y avifauna (Tara, Pujsa, Soncor y Aguas Calientes, este último fuera de la Reserva Nacional Los Flamencos).

${ }^{11}$ En sentido contrario, mantienen acuerdos de cooperación en materia de conservación.

${ }^{12}$ Cuando los comuneros de Peine se enteraron que el subsuelo de su aldea había sido inscrita como pertenencia minera por una de las empresas activas en el Salar de Atacama evaluaron aquello como un abuso y despropósito.

${ }^{13}$ Las Áreas de Desarrollo Indígena (ADI) constituyen un instrumento de concertación público-indígena Desde la perspectiva de las organizaciones indígenas la delimitación territorial de las ADI sirve también al propósito de construir argumentos más sólidos para las demandas por derechos sobre tierras y otros recursos.

${ }^{14}$ El Consejo Nacional Indígena de la CONADI incluye un consejero nacional atacameño. La acción de este consejero puede tener consecuencias positivas para presionar por el cumplimiento de proyectos y programas, proponer otros, plantear denuncias, solicitar la intervención de organismos competentes, etc.

${ }^{15}$ Inicialmente incluía a todas las comunidades indígenas atacameñas y quechuas de la zona, pero en Octubre de 2009 se separa en dos Consejos autónomos: el de Alto Loa y del Salar de Atacama.

${ }^{16}$ Información y algunos análisis complementarios en Gundermann (2013) y Gundermann et al. (2018).

${ }^{17}$ La laguna de Chaxa fue en 2002 concesionada por la CONAF a la Comunidad Indígena de Toconao. La comunidad hace propio y destaca su interés por la conservación del lugar, que perciben y denuncian que se encuentra amenazada por las faenas mineras del Salar.

${ }^{18}$ Sobre estas materias puede consultarse también los artículos de Babidge (2013, 2015).

${ }^{19}$ El Estudio de Impacto Ambiental (EIA) "Cambios y mejoras de la operación minera en el Salar de Atacama" fue presentado el 10 de enero de 2005 y aprobado un año y medio más tarde, el 19 de octubre de 2006, según Resolución de Calificación Ambiental 0226 del Consejo Regional del Medio Ambiente (COREMA) de la Región de Antofagasta.

20 "Convenio de cooperación, sustentabilidad y beneficio mutuo entre comunidad indígena atacameña de Peine y Rockwood Litio Ltda.", firmada el 8 de noviembre de 2012.

${ }_{21}$ "Convenio de cooperación, sustentabilidad y beneficio mutuo entre Consejo de Pueblos Atacameños, Comunidad Indígena Atacameña de Rio Grande y otras y Rockwood Litio Ltda.", suscrito con el Consejo de Pueblos Atacameños y todas las comunidades del Salar de Atacama, mismas del Área de Desarrollo Indígena Atacama La Grande y de la jurisdicción del Municipio de San Pedro de Atacama, el 21 de febrero de 2016.

${ }^{22}$ Bajo el predicamento de: "Mantener una relación de buen vecino y participar del desarrollo de las comunidades cercanas a sus operaciones, apoyando proyectos y actividades conducentes a mejorar su calidad de vida, enfatizando la educación, la cultura y la protección del entorno“, en Reporte SQM sustentable (2014:37).

${ }^{23} \mathrm{Y}$ percibiendo una oportunidad favorable por la posición de debilidad relativa que en esta materia se encontraba por ese entonces SQM.

${ }^{24}$ Rockwood Lithium ingresó en 2009 al Servicio de Evaluación Ambiental (SEA), a cuatro meses de la entrada en vigencia del Convenio 169 de la OIT (el 15 de septiembre de 2009), el estudio de impacto ambiental denominado "EIA Modificaciones y mejoramiento del sistema de pozas de evaporación solar en el Salar de Atacama”. Este estudio vivió una larguísima tramitación, ya que apenas el 20 de enero de 2016 se le entregó a Rockwood Lithium una Resolución de Calificación Ambiental (RCA) favorable.

${ }^{25}$ Empleo directo e indirecto, oferta de servicios menores, asistencia, transferencias monetarias ocasionales, financiamiento de algún proyecto, etc.

${ }^{26}$ Existen riesgos de conflicto interno, faccionalismo, corrupción, autoritarismo, diferenciación, etc. Estos fenómenos existen por otras y variadas causas y podrían verse intensificados aún más. 